\title{
RANCANG BANGUN JARINGAN KOMPUTER DENGAN KABEL LISTRIK SEBAGAI MEDIA TRANSMISI UNTUK KOMUNIKASI DATA
}

\author{
Ricky Firmansyah \\ Teknik Informatika \\ Universitas BSI Bandung \\ Jalan Sekolah Internasional No. 1-6 Antapani, Bandung 40282 \\ ricky.rym@bsi.ac.id
}

\begin{abstract}
Computer network has been implemented in some areas one of which is education, especially primary and secondary schools. Computer networks can be used to share resources and Internet connection between computers in a network. But to build a computer network, infrastructure limitations and Human Resources (HR) become a serious problem in primary and secondary schools. So the computer network and the Internet cannot reach all of the school environment. This study proposes the implementation of a Power Line Communication (PLC) as the transmission medium for data communication with the method of Peer to Peer (P2P) architecture. By using the Power Line Adapter, each room in the school environment can be connected to the network via existing electrical wiring. In addition, no special equipment needed for expert and installation because it can be easily thereby saving the cost budget.Computer Networks with Power Line Communication (PLC) can be used to build a Local Area Network (LAN) using a existing electrical wiring. The results showed that computer networks with Power Line Communication (PLC) as the transmission for the communication of data to easily and improve efficiency for schools in accordance with their needs than building a large network infrastructure.
\end{abstract}

Keywords: internet, computer network, PLC, transmission media

\begin{abstract}
Abstrak - Jaringan komputer sudah diimplementasikan pada beberapa bidang salah satunya adalah bidang pendidikan khususnya sekolah dasar dan menengah. Jaringan komputer dapat digunakan untuk berbagi sumber daya dan koneksi Internet antar komputer dalam jaringan. Namun untuk membangun jaringan komputer, keterbatasan infrastuktur dan Sumber Daya Manusia (SDM) menjadi permasalahan serius di sekolah dasar dan menengah. Sehingga jaringan komputer dan Internet tidak dapat menjangkau seluruh lingkungan sekolah tersebut. Penelitian ini mengusulkan implementasi dari Power Line Communication (PLC) sebagai media transmisi untuk komunikasi data dengan metode Peer to Peer (P2P) arsitektur. Dengan menggunakan perangkat Power Line Adapter, setiap ruangan yang ada di lingkungan sekolah tersebut dapat terhubung dengan jaringan melalui kabel listrik yang ada. Selain itu, tidak diperlukan ahli dan peralatan khusus untuk instalasi karena dapat dilakukan dengan mudah sehingga menghemat biaya anggaran. Jaringan komputer dengan Power Line Communication (PLC) dapat digunakan untuk membangun jaringan komputer lokal (LAN) dengan menggunakan media kabel listrik yang sudah ada. Hasil penelitian menunjukan bahwa jaringan komputer dengan Power Line Communication (PLC) sebagai media transmisi untuk komunikasi data memberikan kemudahan dan meningkatkan efisiensi bagi sekolah sesuai dengan kebutuhannya dibandingkan dengan membangun infrastruktur jaringan yang besar.
\end{abstract}

Kata Kunci : internet, jaringan komputer, PLC, media transmisi

\section{PENDAHULUAN}

Seiring dengan masyarakat kita yang semakin modern, informasi dan data biasa dikirim melalui jaringan komputer. Ini karena keandalan jaringan komputer memiliki dampak yang besar pada kualitas transmisi data, banyak organisasi fokus untuk mengevaluasi atau meningkatkan kehandalan jaringan, terutama optimasi kehandalan jaringan (Kuei Lin \& Ta Yeh, 2011 ). Jaringan komputer sudah dikenal oleh masyarakat luas begitupun manfaat yang 
dirasakan dengan adanya teknologi jaringan komputer ini. Skala umum yang digunakan dalam Organisasi adalah Local Area Network (LAN) baik menggunakan kabel maupun nirkabel (Wireless Local Area Network, WLAN).

Ide untuk meningkatkan efisiensi jaringan komputer ini terus bermunculan, salah satunya adalah Power Line Communication (PLC) selanjutnya disebut PLC, yaitu teknologi yang menggunakan infrastruktur listrik untuk transmisi data (Berger, Schwager, \& Garzás, 2013). Pemandangan kabel jaringan yang mengular dapat diminimalisir dengan PLC, karena setiap ruangan yang memiliki kabel listrik sekalipun hanya untuk memasang bola lampu, dapat terhubung dengan jaringan komputer dan mendapat koneksi Internet. Hal inilah yang membuat penelitian ini menjadi lebih menarik mengingat masih jarangnya penggunaan PLC pada jaringan komputer yang ada di sekitar kita.

Penelitian ini fokus pada implementasi PLC agar pada ruangan tidak terjangkau oleh infrastruktur jaringan yang ada dapat terhubung dengan jaringan dan mendapat koneksi Internet. PLC merupakan suatu revolusi dalam mendukung jaringan komputer dalam skala kecil seperti sebuah LAN, termasuk juga memberikan kesederhanaan dalam tugas-tugas pemasangan instalasi untuk menghasilkan jaringan komputer dengan kecepatan yang tinggi (Slamet, 2010).

Penelitian ini bertujuan untuk mengetahui sejauh mana PLC dapat membantu dan memudahkan pekerjaan membangun jaringan LAN pada Organisasi yang sudah memiliki jaringan komputer namun belum menjangkau seluruh ruangan yang ada dan memiliki keterbatasan dalam hal SDM dan anggaran.

Penelitian ini dilakukan di sebuah Sekolah Menengah Pertama (SMP) untuk digunakan oleh Guru yang menginginkan jaringan komputer dan koneksi Internet terhubung ke kelas yang tidak terjangkau infrastruktur sebagai media pembelajaran maupun sebagai alat bantu kegiatan belajar mengajar.

Penelitian dibatasi pada rancang bangun jaringan komputer sebagai implementasi dari PLC untuk menghubungkan jaringan dan koneksi Internet ke ruangan yang tidak terjangkau infrastruktur jaringan seperti sinyal wifi maupun kabel jaringan secara portable sehingga bisa digunakan kapan saja dan di ruangan mana saja.

\section{KAJIAN LITERATUR}

\section{Jaringan Komputer}

Jaringan komputer adalah suatu sistem yang terdiri atas komputer dan perangkat jaringan lainnya yang bekerja sama untuk mencapai tujuan tertentu. Komputer, printer atau perangkat keras lainnya yang terhubung dengan jaringan disebut dengan istilah node (Wibowo, 2010). Tujuan utama dari jaringan komputer adalah untuk berbagi sumber daya, baik itu penggunaan software maupun hardware. Jaringan komputer memungkinkan satu komputer dapat terhubung dengan komputer lainnya di tempat yang berbeda atau berjauhan. Secara umum, berdasarkan skala ukuran jaringan komputer terbagi menjadi 3 (tiga) skala, yaitu :
1. Local Area Network (LAN)
2. Metropolitan Area Network (MAN)
3. Wide Area Network (WAN)

\section{Local Area Network (LAN)}

Jaringan komputer yang digunakan dalam wilayah geografis yang terbatas adalah LAN, misalnya dalam suatu ruang perkantoran, kampus, sekolah dll. Media transmisi yang banyak digunakan pada LAN yaitu kabel UTP (Unshielded Twist Pair) dengan konektor RJ45. LAN juga dapat dibangun dengan menggunakan media transmisi tanpa kabel yang kemudian dikenal dengan istilah Wireless Local Area Netwrok (WLAN), misalnya penggunaan fasilitas hotspot yang disediakan oleh suatu kampus atau sekolah.

\section{Metropolitan Area Network (MAN)}

Adalah jaringan berkecepatan tinggi yang menghubungkan LAN di dalam wilayah metropolitan, seperti kota atau daerah dan menangani komunikasi yang luas diseluruh wilayah tersebut. MAN terdiri atas satu atau beberapa LAN, tetapi mencakup wilayah yang lebih kecil dari WAN. Misalkan jaringan komputer antara suatu Bank Pusat dengan Bank Kantor Cabang Pembantu di daerah.

\section{Wide Area Network (WAN)}

Adalah jaringan yang mencakup wilayah yang luas (seperti kota, daerah atau negara) menggunakan saluran telekomunikasi (communication channel) yang menggabungkan berbagai macam media seperti jalur telepon, kabel dan gelombang radio. WAN dapat menjadi jaringan yang besar atau dapat terdiri atas dua atau beberapa LAN yang terhubung bersamaan. Internet merupakan WAN terbesar di dunia. 
Sedangkan berdasarkan arsitekturnya, jaringan komputer terbagi menjadi 2 (dua), yaitu :

1. Client-Server

2. Peer to peer $(\mathrm{P} 2 \mathrm{P})$

\section{Client-Server}

Client-Server adalah arsitektur jaringan komputer dimana komputer server sebagai penyedia layanan dan komputer client sebagai penerima layanan (Shelly \& Vermaat, 2012). Beberapa server yang disebut dedicated server, mengerjakan tugas yang spesifik dan dapat ditempatkan bersamaan dengan dedicated server lainnya untuk mengerjakan berbagai tugas. Contohnya, server file bertugas menyimpan dan mengelola file, server print pengelola dan melakukan pencetakanm server basis data menyimpan dan memberi akses pada basis data dan server jaringan mengatur lalu lintas (aktivitas) jaringan.

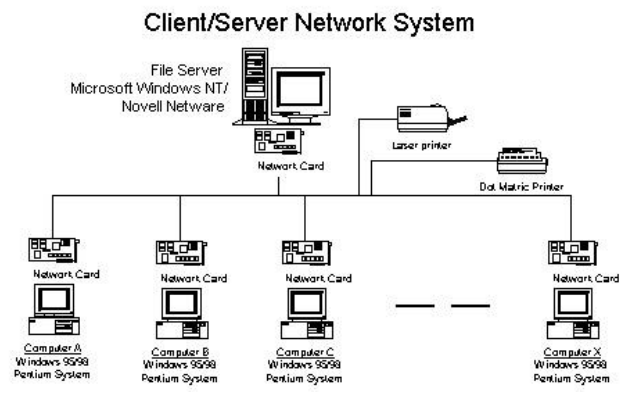

Gambar 1

Arsitektur Client-Server

\section{Peer To Peer (P2P)}

Dalam model jaringan $\mathrm{P} 2 \mathrm{P}$, masingmasing komputer pada jaringan dapat bertindak baik sebagai server dan klien sehingga dapat mendistribusikan beban jaringan yang terletak di semua perangkat pada jaringan, membentuk jaringan rekan-rekan individu dengan kemampuan untuk mencari jaringan untuk sumber daya bersama . Arsitektur P2P memiliki karakteristik keandalan, mudah komunikasi satu ke satu, dan distribusi sumber daya dapat dengan mudah

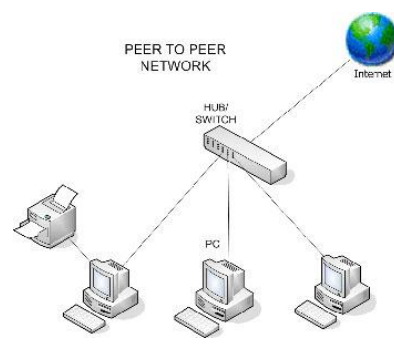

diperpanjang (Abiona, et al., 2013).

Gambar 2

Arsitektur Peer to peer (P2P)
Peer to peer $(\mathrm{P} 2 \mathrm{P})$ adalah jaringan sederhana yang tidak mahal, biasanya menghubungkan kurang dari 10 komputer. Setiap komputer yang disebut dengan peer, mempunyai tanggung jawab dan kemampuan yang sama, berbagi perangkat keras (misalnya printer), data dan atau informasi dengan komputer lainnya pada jaringan peer to peer. Setiap komputer menyimpan file pada perangkat penyimpanannya sendiri.

\section{Power Line Communication}

Arsitektur Power Line Communication (PLC) terdiri atas 4 elemen perangkat keras, yaitu Main station, Base station, Conditioning Unit, dan Customer Premises Equipment (CPE) yaitu perangkat pada pengguna akhir yang berupa modem PLC. Main station menghubungkan infrastruktur komunikasi dengan gardu distribusi tegangan rendah induk (240-415 volt). Main station bekerja sebagai pengkonsentrasi kinerja tinggi dari lalulintas protokol Internet (IP) Sinyal-sinyal diinjeksikan ke dalam jaringan tegangan rendah dari jaringan data konvensional eksternal (kabel tembaga koaksial, kabel optik fiber, jaringan nirkabel, atau bahkan jaringan satelit). Prinsip dasarnya adalah menginjeksikan sinyal-sinyal data ke dalam saluran daya listrik pada frekuensi 10 juta kali frekuensi dasar arus listrik (atau sekitar 500/600MHz). Jadi meskipun komunikasi data dapat dipropagasi melalui kabel listrik, beberapa jaringan konvensional harus tetap ada atau diinstal ke gardu distribusi (Febridiani \& Wibisono, 2010).

\section{Power Line Adapter}

Power line adapter adalah satu set perangkat pasangan yang mengirimkan data kecepatan tinggi antara dua panel listrik di berbagai bagian ruangan menggunakan kabel listrik yang ada. Sistem ini menggunakan jaringan listrik tegangan rendah untuk menghubungkan perangkat di rumah, seperti komputer, printer, scanner, serta perangkat rumah lainnya seperti smart devices. Stop kontak digunakan sebagai konsentrator dengan menambahkan adapter ke stop kontak yang akan digunakan sebagai penghubung jaringan (Kuntarto, 2009).

\section{METODE PENELITIAN}

Dalam penelitian ini, pengumpulan data dilakukan dengan menggunakan metode observasi, yaitu mengumpulkan data langsung dari lapangan baik berupa wawancara maupun dokumentasi (Semiawan, 2010). Rancang 
bangun jaringan untuk implementasi PLC sebagai media transmisi ini dilaksanakan pada bulan Februari 2014 di Sekolah Menengah Pertama (SMP) "X". Langkah pertama yang dilakukan adalah melakukan identifikasi rutinitas yang berhubungan dengan penggunaan jaringan komputer, perangkat komputer dan jaringan yang tersedia dan bagian yang berwenang dalam mengatur teknis dan pelaksanaan pengembangan jaringan komputer.

Spesifikasi komputer dan perangkat jaringan statis yang digunakan adalah seperti pada tabel :

Tabel 1

Perangkat statis yang tersedia

\begin{tabular}{llcl}
\hline No & $\begin{array}{c}\text { Nama } \\
\text { Perangkat }\end{array}$ & Qty & Spesifikasi (Merk) \\
\hline 1 & Unit & 3 & P 3.0GHz \\
& Komputer & & RAM 1GB \\
& Ruang TU & & HDD 160GB \\
& & & VGA 64MB \\
& NIC \\
& & & OS Win 7 \\
\hline 2 & Router & 1 & TP-Link \\
\hline 3 & Switch & 1 & TP-Link 8 Port \\
\hline 4 & Access & 1 & Airlive 802.11 G \\
& Point (AP) & & AP Access Point \\
\hline 5 & ISP & 1 & Telkom Speedy \\
\hline 6 & Kanel UTP & 1 & Telebit cat5e \\
\hline 7 & PowerLine & 1 & Tp-Link TL-PA511 \\
& Adapter & & AV500 \\
\hline
\end{tabular}

Dari hasil indentifikasi tersebut didapatkan jalur yang akan digunakan untuk implementasi PLC adalah dengan mengambil sambungan dari switch yang terpasang di ruang Tata Usaha karena ruangan tersebut merupakan pusat jaringan komputer sekolah yang terkoneksi dengan Internet melalui router yang terhubung dengan ISP (Internet Service Provider). Sehubungan dengan jaringan komputer yang ada dibuat seadanya, maka untuk meningkatkan efektifitas kinerja, mempermudah pengembangan dan merapikan administrasi jaringan komputer maka dilakukan pengaturan terlebih dahulu untuk seluruh jaringan komputer yang ada. Dimulai dengan merapikan pengkabelan dan memberikan pengalamatan IP pada semua perangkat statis yang terhubung ke jaringan kecuali komputer yang ada di Laboratorium Komputer karena memiliki pengaturan tersendiri oleh bagian yang berwenang. Adapun pembagian alamat IP adalah sebagai berikut :

$\begin{array}{ll}\text { Router TP-Link } & : 192.168 .1 .1 \\ \text { Access Point } & : 192.168 .1 .2\end{array}$

$\begin{array}{ll}\text { IP tiap komputer } & : 192.168 .1 .3-5 \\ \text { Subnet Mask } & : 255.255 .255 .0 \\ \text { Gateway } & : 192.168 .1 .1 \\ \text { DNS Server (NAWALA) } \\ \text { Prefered DNS } & : 180.131 .144 .144 \\ \text { Alternate DNS } & : 180.131 .144 .144\end{array}$

Metode Peer to peer (P2P) arsitektur digunakan dalam jaringan komputer tersebut, termasuk untuk sambungan yang menggunakan Power Line Adapter. Topologi yang digunakan pada jaringan komputer yang ada adalah topologi star. Topologi Star merupakan topologi di mana semua node dihubungkan melalui suatu node secara terpusat (Wibowo, 2010) dengan metode yang digunakan adalah Peer to peer, yang berarti tiap komputer dapat berperan sebagai client ataupun server sehingga tidak diperlukan adanya server pusat (Hamdani \& Munir, 2012).

Nantinya dari jaringan komputer tersebut, akan diambil satu sambungan kabel UTP yang terhubung dengan jaringan dan koneksi internet yang akan dihubungkan ke Power Line Adapter ke-1 yang sudah terpasang di stop kontak. Selanjutnya Power Line Adapter ke-2 ditempatkan di ruangan kelas yang ingin terhubung dengan jaringan komputer melalui kabel listrik yang tersedia di ruangan tersebut. Power Line Adapter ke-3, ke-4 dan seterusnya dapat disesuaikan dengan kebutuhan. Selain itu, Power Line Adapter dapat dikombinasikan dengan Acces Point (AP) sehingga dapat juga membuat atau memperluas jangkauan jaringan WLAN (hotspot).

Berikut adalah gambar Rancang Bangun Jaringan Komputer di SMP " $\mathrm{X}$ " :

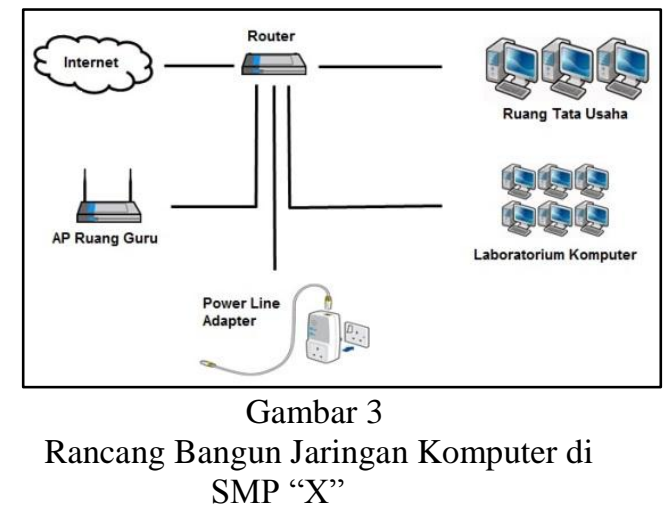

\section{PEMBAHASAN}

Sekolah Menengah Pertama (SMP) " $X$ " memiliki 27 ruang kelas yang semuanya belum terhubung dengan jaringan komputer. Beberapa ruangan yang terhubung dengan jaringan komputer lokal (LAN) antara lain Ruang Tata 
Usaha, Ruang Guru dan Laboratorium Komputer. Begitupun jangkauan WLAN (hotspot) hanya dapat dijangkau oleh ketiga ruangan itu saja karena Access Point (AP) terletak di Ruang Guru yang letaknya tidak berjauhan dengan dua ruangan lainnya. Setelah sebelumnya melakukan perngorganisasian terhadap jaringan komputer yang ada, barulah dilakukan pengetesan koneksi dari Power Line Adapter ke-1 ke Power Line Adapter ke-2 dengan cara memasang Power Line Adapter $k e-2$ di ruangan kelas yang akan digunakan sebagai ruang percobaan. Power Line Adapter yang digunakan pada penelitian ini memiliki spesifikasi sebagai berikut :

$\begin{array}{ll}\text { Merk/Tipe } & : \text { TP-Link TL511 AV500 } \\ \text { Standar } & : \text { IEEE802.3/3u } \\ \text { Data Rate } & : \text { 500Mbps } \\ \text { Range } & : \text { 300 meters } \\ \text { Interface } & : \text { 1 Ethernet LAN Port } \\ \text { Power } & : 6 \mathrm{~W}\end{array}$

Power Line Adapter ke-2 dipasang langsung pada stop kontak yang ada di kelas dengan tanpa menggunakan kombinasi listrik tambahan sesuai dengan prosedur yang ada pada gambar berikut :

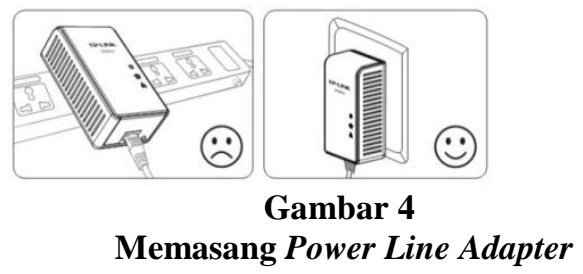

Setelah Power Line Adapter terpasang dengan baik pada stop kontak, berikutnya adalah menghubungkan Power Line Adapter pada laptop memalui kabel UTP pada masingmasing port Ethernet yang ada dikedua perangkat. Kemudian memastikan bahwa Power Line Adapter sudah terhubung dengan baik yang ditandai dengan ikon network terhubung pada laptop dan semua lampu indikator pada Power Line Adapter menyala yakni lampu indikator Power,LED, Ethernet LED dan Power Line LED seperti ditunjukkan pada gambar berikut :

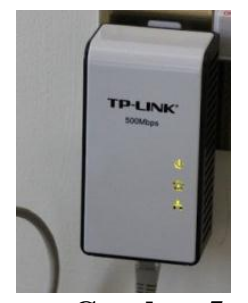

Gambar 5

Semua LED indikator menyala
Berikutnya adalah melakukan tes koneksi di laptop menggunakan perintah "ping" pada command prompt dengan mengetikan ping 192.168.1.1 $-\mathrm{t}$ diakhiri dengan menekan tombol Enter. Maksud dari perintah tersebut adalah untuk mengetahui apakah jaringan sudah terhubung atau belum dan melihat respon yang diberikan dari alamat IP 192.168.1.1 yaitu alamat IP yang digunakan oleh perngkat Router yang ada di ruangan Tata Usaha sekaligus menjadi Gateway untuk koneksi Internet. Dalam hal ini, Router memberikan respon namun terdapat keterangan "request time out" yang menandakan bahwa alamat IP tersebut tidak merespon yang bisa diakibatkan oleh kurang stabilnya koneksi ataupun sibuknya jaringan yang menuju alamat IP tersebut. Hal tersebut juga dapat terjadi diakibatkan karena kurang baiknya infrasruktur yang ada. Dalam penelitian ini, kualitas kabel listrik yang ada memang tidak diketahui kualitasnya akan tetapi sangat jarang terjadi "request time out" sekalipun ada. Berikut adalah gambar hasil tes koneksi ke alamat IP 192.168.1.1:

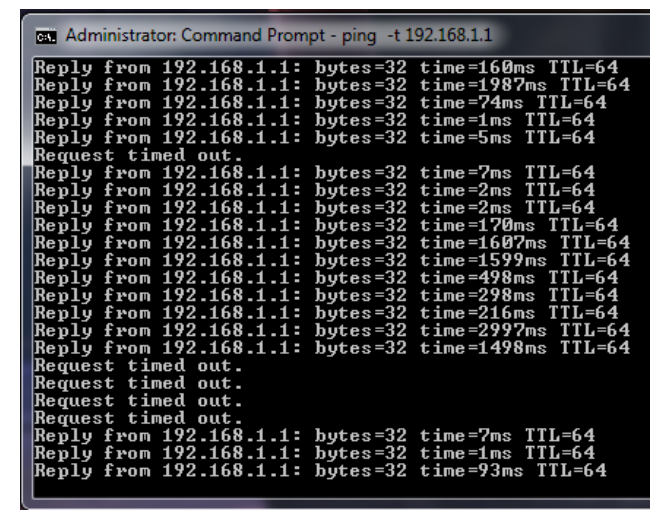

\section{Gambar 6}

Tes koneksi Power Line Adapter

Dalam paket pembelian Power Line Adapter ini, diberikan juga CD yang berisi pogram utilitas yang digunakan untuk membantu mengelola jaringan yang terhubung menggunakan Power Line Adapter.

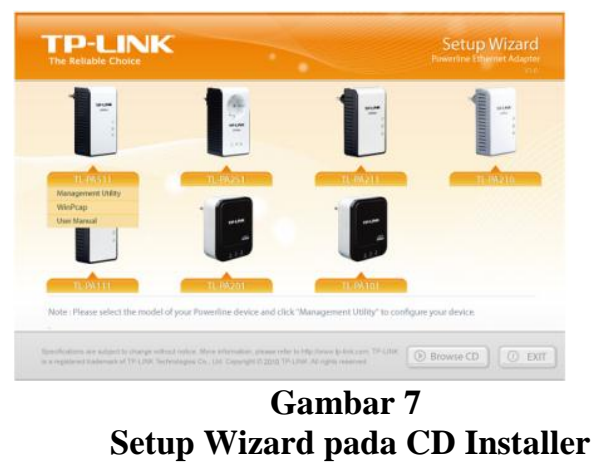


Pada saat CD dimasukan ke dalam optical drive, secara otomatis wizard akan terbuka karena menggunakan sistem autorun. Langkah untuk menginstal program utilitas ini sama mudahnya dengan mengnistal program aplikasi pada umumnya yaitu tinggal menekan tombol "Next" dan diakhiri dengan menekan tombol "Finish".

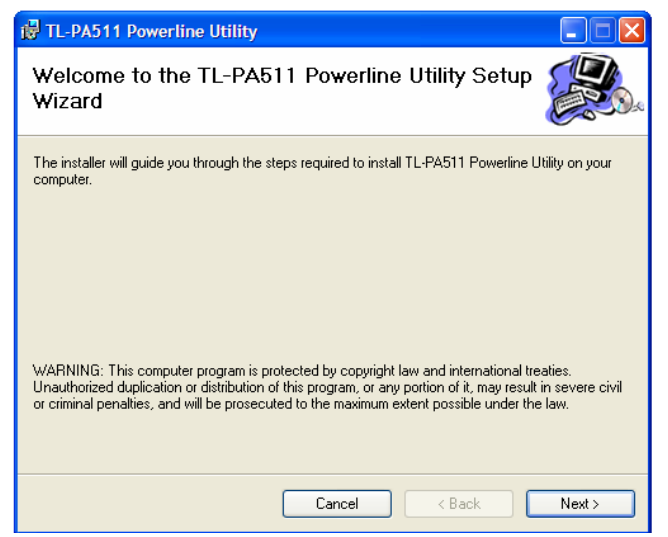

\section{Gambar 8}

TL PA511 Utility Setup

Perangkat Power Line Adapter tidak memerlukan driver khusus karena akan terbaca sebagai perangkat Ethernet pada Laptop atau komputer. Namun, dengan menggunaan program utilitas yang disediakan, pengguna akan lebih mudah memonitor kondisi Power Line Adapter yang terhubung dalam jaringan tersebut khususnya apabila menggunakan lebih dari 2 Power Line Adapter.

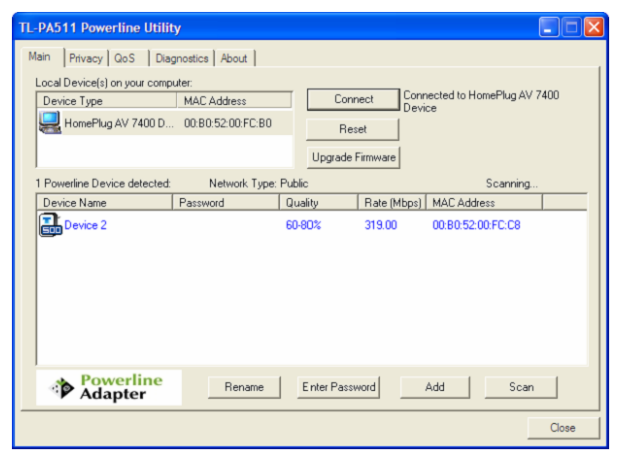

\section{Gambar 9}

TL PA511 Utility

Pada gambar di atas, terlihat bahwa perangkat Power Line Adapter ke-2 sudah terdeteksi oleh utilitas. Untuk menghubungkan komputer dengan Power Line Adapter ke-2, klik "connect" pada utilitas dan selanjutnya kita akan diminta memasukan password sebagai fasilitas keamanan yang diberikan oleh Power Line Adapter. Apabila password yang diinputkan benar, maka perangkat akan terhubung. Password tersebut dapat diatur secara oleh pengguna pada program utilitas seperti pada gambar berikut :

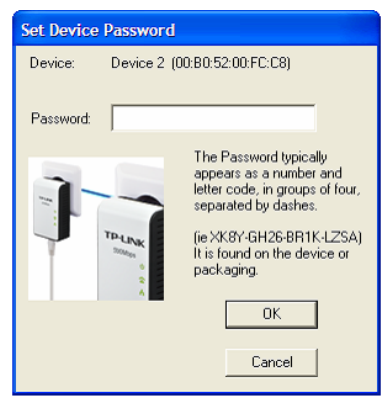

Gambar 10

Set Password TL PA511

Sampai disitu implementasi Power Line Adapter sebagai media transmisi untuk komunikasi data sudah dapat digunakan, baik sebagai jaringan komputer biasa maupun berbagi koneksi Internet bahkan dapat digunakan untuk memperluas jangkauan hotspot yaitu dengan menghubungkan Power Line Adapter ke-2 dengan perangkat Access Point (AP). Skema sederhana mengenai penggunaan Power Line Adapter ini dapat dilihat pada gambar berikut :

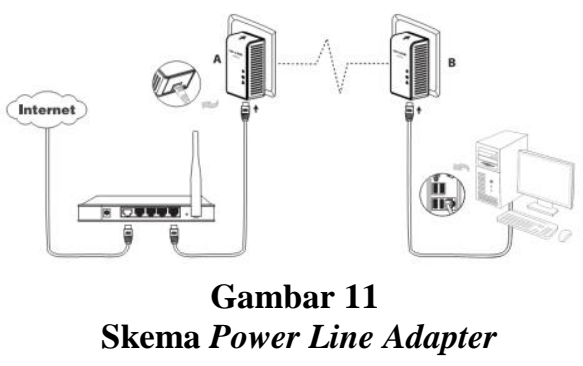

Gambar di atas memperlihatkan bagaimana Power Line Adapter ke-1 (A) dihubungkan dengan Router yang terkoneksi dengan Internet dan terhubung Power Line Adapter ke-2 (B) melalui kabel listrik yang ada. Selain itu, penggunaan Power Line Adapter bisa ditambahkan sesuai dengan kebutuhan, misalnya menggunakan lebih dari 2 Power Line Adapter. Namun, pada paket penjualan hanya diberikan sepasang (2 unit). Contohnya menambahkan Power Line Adapter $\mathrm{C}$ seperti ditunjukkan pada gambar berikut :

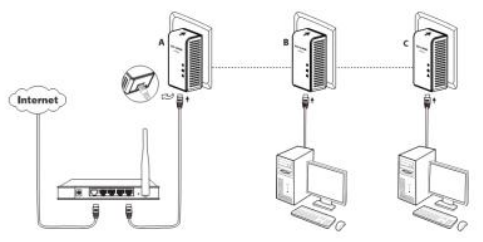

Gambar 12

Skema penambahan node Power Line Adapter 
Hasil dari penelitian ini adalah bahwa Guru di SMP "X" dapat terhubung dengan jaringan komputer maupun koneksi Internet di kelas yang tidak terjangkau oleh infrastruktur jaringan yang ada. Selain itu, secara fleksibel perangkat Power Line Adapter dapat dilepas dan dibawa ke ruangan kelas lainnya yang ingin terhubung dengan jaringan komputer dan Internet.

\section{PENUTUP}

\section{Kesimpulan}

Dari penelitian ini, dapat diambil beberapa kesimpulan sebagai berikut :

1. Rancang bangun jaringan komputer dengan kabel listrik sebagai media transmisi untuk komunikasi data ini memberikan kemudahan bagi Guru maupun karyawan yang secara fleksibel dapat terhubung dengan jaringan komputer di kelas atau ruangan lain tanpa menambahkan kabel baru.

2. Pengembangan jaringan komputer dan perluasan jangkauan hotspot dapat dilakukan dengan mudah.

3. Harga Power Line Adapter masih cukup tinggi sehingga karena keterbatasan anggaran, pemakaian perangkat ini digunakan secara bergantian.

4. Spesifikasi Power Line Adapter yang digunakan masih dapat terhubung hingga jarak 300 meter, namun belum diuji pada gardu listrik yang berbeda oleh karena itu perlu pengujian lebih lanjut untuk mengetahui akurasi dari spesifikasi tersebut.

\section{REFERENSI}

Abiona, O., Oluwaranti, A., Anjali, T., Onime, C., Popoola, E., Aderounmu, G., et al. (2013). Architectural Model for Wireless Peer-to-Peer (WP2P) File Sharing for Ubiquitous Mobile Devices. IEEE International Conference on Electro/Information Technology, 35-39.

Berger, T. L., Schwager, A., \& Garzás, J. J. (2013). Power line communications for smart grid applications. Journal of Electrical and Computer Engineering
- Special issue on Power-Line Communications: Smart Grid, Transmission, and Propagation, 3.

Febridiani, L. D., \& Wibisono, G. (2010). Analisis SWOT untuk Implementasi Voice over Internet Protocol (VoIP) pada Powerline Communication (PLC). Jurnal Informatika LIPI, 1-7.

Hamdani, R., \& Munir, R. (2012). Aplikasi Sinkronisasi File dengan Metode Peer-to-peer. Prosiding Teknik Elektro \& Informatika, Volume 1, Nomor 1 (pp. 1-6). Bandung: Institut Teknologi Bandung.

Kuei Lin, Y., \& Ta Yeh, C. (2011 ). Using minimal cuts to optimize network reliability for a stochastic computer network subject to assignment budget. Computers and Operations Research, 1175-1187.

Kuntarto, G. P. (2009). TEKNOLOGI POWER LINE COMMUNICATIONS (PLC) BERKAITAN DENGAN ASPEK TEKNIK DAN EKONOMI. ULTIMATICS VOL. 1 NO. 1, DESEMBER 2009 Universitas Multimedia Nusantara, 7-12.

Semiawan, R. (2010). Metode Penelitian Kualitatif. Jakarta: Grasindo.

Shelly, G., \& Vermaat, M. (2012). Discovering Computers, Complete: Your Interactive Guide to the Digital World. Boston, MA 02210: Course Technology.

Slamet, L. (2010). MEMBANGUN JARINGAN KOMUNIKASI DATA DENGAN KABEL LISTRIK JALAJALA $50 \mathrm{~Hz}$ SEBAGAI MEDIA TRANSMISI )IMPLEMENTATION . JURNAL TEKNOLOGI INFORMASI \& PENDIDIKAN , 93-99.

Wibowo, A. (2010). Cara Mudah Membangun LAN. Jakarta: PT. ELex Media Komputindo. 